\title{
Single-Site Robotic Radical Hysterectomy and Sentinel Lymphnode Biopsy in Cervical Cancer: A Case Report
}

\section{Histerectomia radical robótica de portal único e biópsia de linfonodo sentinela: relato de caso} \author{
Jesus Paula Carvalho ${ }^{1,2}$ \\ ${ }^{1}$ Centro de Oncologia, Hospital Alemão Oswaldo Cruz, São Paulo, Brazil \\ 2 Department of Obstetrics and Gynecology, Instituto do Câncer do \\ Estado de São Paulo (ICESP); Faculdade de Medicina da Universiade \\ de São Paulo, SP, Brazil \\ ${ }^{3}$ Departament of Pathology, Faculdade de Medicina, Universidade de \\ São Paulo, São Paulo, Brazil \\ ${ }^{4}$ Department of Advanced Gynecologic Surgery and Oncology, \\ Asklepios Hospital, Hamburg, Germany
}

Alexandre Silva e Silva ${ }^{1,2}$ Rodrigo Pinto Fernandes ${ }^{1,2}$ Marcia Pereira de Araujo ${ }^{1,2}$

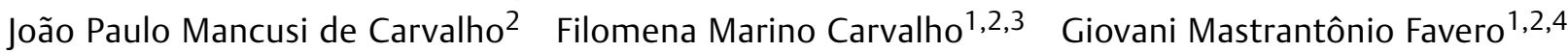

\begin{abstract}
Address for correspondence Jesus Paula Carvalho, MD, PhD, Centro de Oncologia do Hospital Alemão Oswaldo Cruz, Rua Frei Caneca 558cj 1014, 01307-000 - São Paulo, Brazil (e-mail: jpcarvalho@usp.br).
\end{abstract}

Rev Bras Ginecol Obstet 2016;00:35-40.
Abstract
Keywords
- hysterectomy
- cervical cancer
- single-site robotic laparoscopy
- lymphadenectomy
- robotics
- laparoendoscopic single-site surgery

\section{Resumo \\ Palavras-chave \\ - histerectomia \\ - câncer do colo do útero \\ - laparoscopia robótica de sítio único \\ - linfadenectomia \\ - robótica \\ - cirurgia laparoendo- scópica de sítio único}

Robotic surgeries for cervical cancer have several advantages compared with laparotomic or laparoscopic surgeries. Robotic single-site surgery has many advantages compared with the multiport approach, but its safety and feasibility are not established in radical oncologic surgeries. We report a case of a Federation of Gynecology and Obstetrics (FIGO) stage IB1 cervical carcinoma whose radical hysterectomy, sentinel lymph node mapping, and lymph node dissection were entirely performed by robotic single-site approach. The patient recovered very well, and was discharged from the hospital within 24 hours.

A cirurgia robótica para carcinoma do colo do útero apresenta vantagens quando comparada com cirurgias laparotômicas ou laparoscópicas. A cirurgia robótica de portal único tem muitas vantagens quando comparada com cirurgias de múltiplos acessos, porém a segurança e a viabilidade deste procedimento ainda não estão estabelecidas para cirurgias oncológicas radicais. Apresentamos um caso de carcinoma de colo do útero, tratado por histerectomia radical, identificação e biópsia de linfonodo sentinela e linfadenectomia pélvica realizada totalmente por cirurgia robótica de acesso único. A paciente recuperou-se bem e recebeu alta no primeiro dia pósoperatório. received

June 11,2016

accepted

November 17, 2016

published online

December 30, 2016
DOI http://dx.doi.org/

10.1055/s-0036-1597752. ISSN 0100-7203.
Copyright $(2017$ by Thieme-Revinter

Publicações Ltda, Rio de Janeiro, Brazil
License terms

(c) (1) $\ominus$ (\$) 


\section{Introduction}

Laparoscopic and robotic surgeries for cervical cancer are becoming the standard surgical treatment in most oncologic centers around the world. These procedures have several advantages compared with laparotomic surgeries, including improved quality of life and better surgical outcomes. ${ }^{1}$

Most minimally invasive surgeries, laparoscopic or robotic, are already being performed by a multiport approach, which is responsible for some risks, such as pain, bleeding, hernia, or infection associated with multiple incisions. ${ }^{2}$

The concept of laparoendoscopic single-port surgery emerged as a procedure less invasive than multiport laparoscopy, and it was recently incorporated by robotic surgery. Robotic single-site surgery has many advantages compared with the multiport approach, ${ }^{3-6}$ but its safety and feasibility are still being investigated in radical oncologic surgeries.

\section{Case Report}

Patient: a 42-year-old, multiparous, two previous C-section patient was diagnosed, by cold-knife cone biopsy, with a Federation of Gynecology and Obstetrics (FIGO) stage IB1 cervical adenosquamous cell carcinoma. The body mass index was 21.3. The physical examination showed no visible residual disease. The magnetic resonance imaging examination showed a cervical tumor of $1.8 \mathrm{~cm}$, without any radiologic signs of deep invasion or lymph node enlargement. The patient underwent a robotic single-site radical hysterectomy and sentinel lymph node mapping using indocyanine green followed by complete pelvic lymph node dissection.

Surgical technique: The patient under combined anesthesia was placed in the semidorsal lithotomy position and then drapped. After bladder catheterization, a speculum was placed for cervical visualization, and $1 \mathrm{mg}$ indocyanine green was injected into the cervix $(0.5 \mathrm{mg} / \mathrm{ml}$ at 3 and 9 hours; - Fig. 1) in order for the sentinel lymph node mapping to be detected by SPY fluorescence image (SPY System;

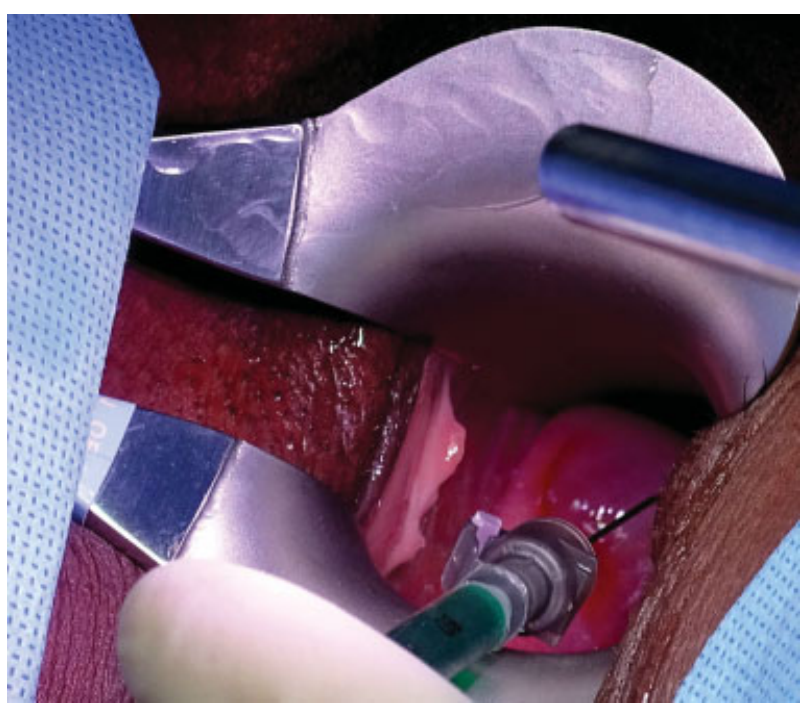

Fig. 1 Cervical injection of indocyanine green (1 $\mathrm{ml}$ on each side).

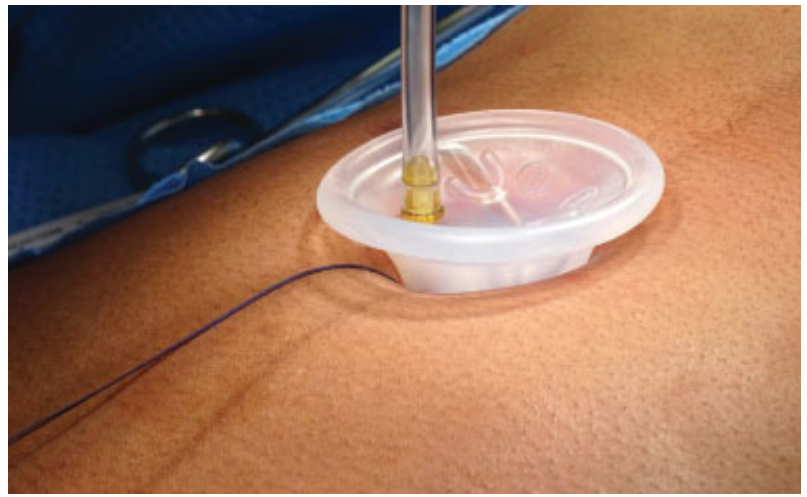

Fig. 2 Single-site port. The five-lumen port provides access for two single-site instruments: the $8.5 \mathrm{~mm}$ 3DHD endoscope, a 5/10 mm accessory port, and an insufflation adapter.

Novadaq Technologies, Concord, ON, Canada). Cervical dilatation was performed, and a Clermont Ferrant uterine manipulator (Karl Storz GmbH \& Co. KG, Tuttlingen, Germany) was fixed onto the cervix. The access was performed through the umbilicus, in the midline. A $2.5 \mathrm{~cm}$ incision was made using all the umbilical scar length, opening the peritoneal cavity and double-checking the security of this entrance. The single-site port was inserted into the abdominal cavity using an atraumatic forceps, and the arrow drawn on the port was set in the direction of the target organ (uterus and pelvic nodes; -Fig. 2). The pneumoperitoneum was low flow inflated at a pressure of $15 \mathrm{mmHg}$. The trendelemburg position was applied, and the bowel was placed with a laparoscopic grasper through the assistant place. The da Vinci ${ }^{\circledR}$ Xi System (Intuitive Surgical, Sunnyvale, CA) was docked between the patient's legs. A 3D $8.5 \mathrm{~mm}$ endoscope was used in the camera arm, and a monopolar hook and a bipolar Maryland forceps were used on the right and left hands respectively. Adhesiolysis from the epiploon and anterior abdominal wall was performed to improve the vision and surgical field. The near-infrared (NIR) image SPY highlighted in fluorescent green three retroperitoneal nodules, two on the right and one on the left. On the right side, one nodule was located in the bifurcation of the external and internal iliac arteries, and the other was medial of the right common iliac artery lateral to the left common iliac vein. On left side we identified three sentinel nodes between internal

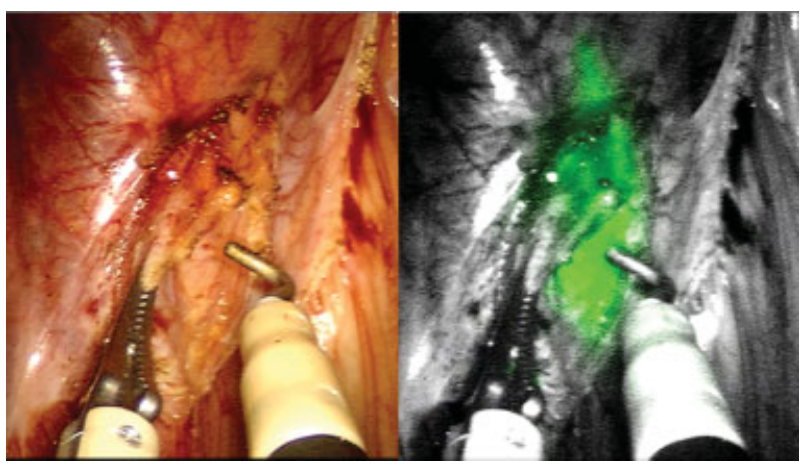

Fig. 3 Sentinel lymph node mapping with indocyanine green. 
and external iliac arteries. The three sentinel lymph nodes were collected ( $\boldsymbol{\text { Fig. }} \mathbf{3}$ ) for pathological ultrastaging. No frozen section was realized. The t-lift $\AA$ device (Vectec, Hauterive, France) was used for bilateral ovary suspension. The posterior U-cut, a Puntambekar et $\mathrm{al}^{7}$ technique, was performed to expose both ureters. A bilateral salpingectomy followed for the anterior peritoneum and bladder dissection from the uterus on the caudal direction. The uterine artery was coagulated with a bipolar Maryland forceps close to the internal iliac artery, and the parametrial anterior dissection was performed bilaterally with ureteral tunnelization until the bladder. Hypogastric nerves were identified bilaterally and saved. A Querleu/Morrow type C1 radical hysterectomy was performed. A bilateral pelvic lymph node dissection was performed using only bipolar and monopolar energy from the ForceTriad platform (Covidien; Medtronic, Minneapolis, MN, US). No vessel sealing or ultrasonic energy was used. All surgical specimens were extracted from the abdominal cavity through the vagina, without any bag. A careful hemostasis was performed before the vaginal cuff closure. The vaginal cuff closure was started internally, but was aborted due to the absence of the single-site needle driver, and was done vaginally with Caprofyl 2-0 (Caprofyl ${ }^{\circledR}$, Ethicon Inc, Bridgewater, NJ, US). The robot was undocked, and the single-site port was taken out. The umbilical incision was sutured in planes with number 2 prolene thread on the aponeurosis, and monocryl 4-0 (Ethicon, Cornelia, Georgia, US) under the skin (-Fig. 4).

Pathological examination: The uterus weighed $85 \mathrm{~g}$ and measured $8.8 \times 5.0 \times 3.2 \mathrm{~cm}$. There was bilateral parametrial and vaginal cuff. The gross examination of the specimen revealed an ulcer in the periorificial cervical area (-Fig. 5). The histological examination revealed a histological grade 2 cervical adenosquamous carcinoma measuring $3.0 \times 2.1 \times 1.8 \mathrm{~cm}$ associated with multifocal lymphovascular space invasion. The maximum level of infiltration of the cervical wall was $0.7 \mathrm{~cm}$ (54\% thickness). The parametrial and vaginal cuff as well as the surgical margins were free of neoplasia. There was an intraparametrial lymph node with metastasis. The three

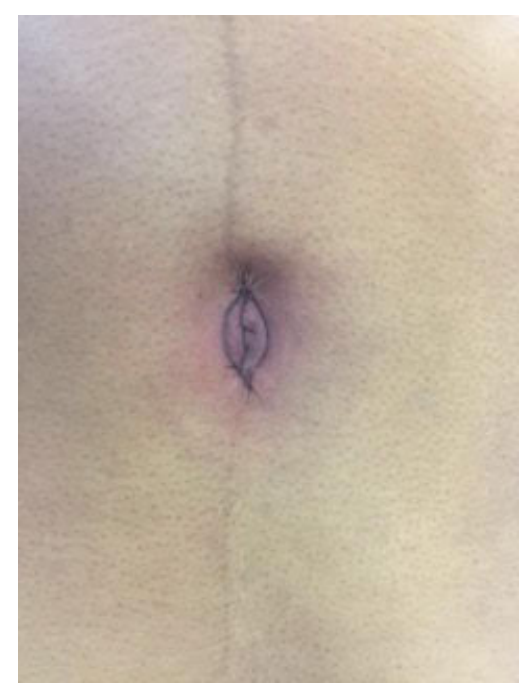

Fig. 4 Umbilicus at the end of the surgery.

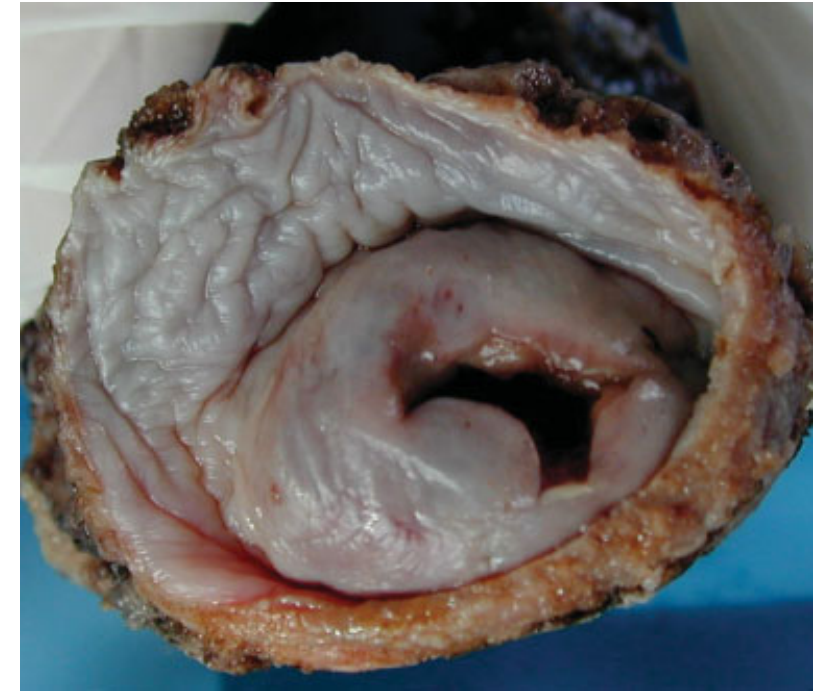

Fig. 5 Surgical specimen: uterus and vaginal margins.

sentinel lymph nodes and the pelvic lymph nodes dissected (8 to the left pelvic chain and 9 to the right) were free, totalizing a nodal status of $1 / 21$.

Evolution: The patient recovered very well, and was discharged from the hospital after 24 hours.

\section{Discussion}

Cervical cancer remains highly prevalent worldwide, particularly in lower- and middle-income economies. The standard treatment for early-stage cervical cancer is radical hysterectomy, which, although effective, is associated with serious morbidities. A systematic review and meta-analysis was conducted to compare the intraoperative and postoperative complications of robotic radical hysterectomy and other surgical methods. Robotic surgery is superior to abdominal surgery, with lower blood loss, shorter hospital stay, lower febrile morbidity, and lower wound-related complications. ${ }^{8}$ Robotic and laparoscopic surgeries are comparable in the same study. The laparoendoscopic single-site access reduces postoperative pain and analgesia use compared with the multiport conventional laparoscopy in a benign disease. ${ }^{9}$ Although laparoendoscopic radical hysterectomy with pelvic lymphadenectomy appears safe and feasible, ${ }^{10}$ it has not gained wide acceptance due to a lack of flexibility inside the cavity. The robotic approach for single-site procedures has the potential advantage of better surgeon comfort.

Robotic laparoendoscopic single-site radical hysterectomy for uterine malignancies is a very recent and innovative surgical procedure, wherein the surgeon operates exclusively through a single skin incision within the umbilicus. This procedure evolved from laparoscopic single-port and multiport robotic surgery, with many advantages. It is expected to have lesser complications from multiple access and better cosmesis, like single-port laparoscopy, but under more ergonomic conditions for the surgeon. The procedure has been reported as feasible and safe in benign conditions, although 
there are only a few cases reported with this approach for gynecologic cancers. ${ }^{3,11-14}$ In a retrospective case-control study comparing robotic single-site to robotic multiport hysterectomy in early-stage endometrial cancer, Corrado et $\mathrm{al}^{14}$ found similar operative times, lower blood loss, lower hospital stay days, and lower costs with the single-site approach. $^{14}$

The single-site approach comes as an upgrade of the minimally invasive surgeries, first of all, because of the cosmetic results. It is unquestionable that one umbilical single incision looks better than two or more surgical wounds, and this is an important factor for cancer patients and their self-esteems. Nevertheless, some technical issues should be considered. Surgeons are obliged to deal with arched instruments that cross through the single-site device reaching the cavity in an inverted position. Assistants holding the camera must keep their arm in between the surgeon's hands, conflicting with the first approach and causing image instability. Inside the cavity, the instruments lack triangulation and flexibility. One by one, all of these few details compromise the surgeon's capability, leading to a decrease in performance and an increase in the risks. ${ }^{15}$

Robotic surgery improved surgical gestures such as camera stability, less tremors, articulated instruments, and 3D visualization. Likewise, single-site robotic surgery developed not only with previous robotic characteristics, like a superior range of motion, but also by canceling the crossing effect of instruments. The software allows the surgeon to control the ipsilateral device as seen on screen. The surgeon's ergonomy is also improved. The doctor remains in a chair, with arms resting on a comfortable support while controlling the instruments. The available single site for the da Vinci ${ }^{\circledR}$ Xi System with lack of wrist movement represents a downgrade compared with the conventional multiport robotic approach. An important detail is that it not only obliges the surgeon to be experienced in classic laparoscopic gestures, but also requires that the whole surgical team be extremely synchronized. A simple suction and irrigation procedure requires a close collaboration between the console surgeon and the bedside assistant.

The latest da Vinci ${ }^{\circledR}$ Xi System was upgraded with articulated instruments, and brings some advantages back. Several snake-like robots are currently under development. The flexible architecture and multiple degrees of freedom make this concept the most suitable one for robotic single-site surgeries. ${ }^{16}$

In the era of minimally invasive surgeries and significant advances in adjuvant therapies and imaging methods, the role of systematic lymphadenectomies is under debate, and, in many cancers, they have been replaced by less extensive procedures, such as sentinel lymph node biopsy. There are increasing data to suggest that sentinel lymph node mapping for cervical cancer is a sensitive tool in the detection of lymph node metastasis. ${ }^{17}$ The traditional techniques of sentinel lymph node mapping use blue dyes (isosulfan or methylene blue) and radiolabeled isotopes such as technetium 99 (Tc99) microsulfur colloid, alone or in combination. These techniques can be challenging to master with prolonged learning curves. $^{18} \mathrm{~A}$ new feasible technique was introduced (using indocyanine green and NIR imaging) to detect the sentinel lymph node fluorescing dye. It has the accumulative benefits of visibility (like from the blue dye) and of the penetration of the signal from the intact tissue (from the nuclear tracer techniques) in a single modality. ${ }^{17,19}$ Fluorescence imaging can be used in laparotomic, laparoscopic, and robotic surgeries. ${ }^{17,19-21}$

\section{Conclusion}

Single-site robotic radical hysterectomy is a feasible procedure in early-stage invasive cervical cancer. In our case, indocyanine green mapping allowed us to identify sentinel lymph nodes in both sides, all of them negative, as well as all the pelvic lymph nodes. Although a positive intraparametrial microscopic lymph node was found, it was located in the proximal parametrium, just beside the injection area. All resection margins were free of neoplasia.

\section{References}

1 Galaal K, Bryant A, Fisher AD, Al-Khaduri M, Kew F, Lopes AD. Laparoscopy versus laparotomy for the management of early stage endometrial cancer. Cochrane Database Syst Rev 2012;(9):CD006655

2 Shin JH, Howard FM. Abdominal wall nerve injury during laparoscopic gynecologic surgery: incidence, risk factors, and treatment outcomes. J Minim Invasive Gynecol 2012;19(4):448-453

3 Sinno AK, Fader AN, Tanner EJ III. Single site robotic sentinel lymph node biopsy and hysterectomy in endometrial cancer. Gynecol Oncol 2015;137(1):190

4 Yoon A, Yoo HN, Lee YY, et al. Robotic single-port hysterectomy, adnexectomy, and lymphadenectomy in endometrial cancer. J Minim Invasive Gynecol 2015;22(3):322

5 Tateo S, Nozza A, Del Pezzo C, Mereu L. Robotic single-site pelvic lymphadenectomy. Gynecol Oncol 2014;134(3):631

6 Bogliolo S, Musacchi V, Cassani C, Babilonti L, Gardella B, Spinillo A. Robotic single-site technique allows pelvic lymphadenectomy in surgical staging of endometrial cancer. J Minim Invasive Gynecol 2015;22(4):695-696

7 Puntambekar SP, Palep RJ, Puntambekar SS, et al. Laparoscopic total radical hysterectomy by the Pune technique: our experience of 248 cases. J Minim Invasive Gynecol 2007;14(6):682-689

8 Shazly SA, Murad MH, Dowdy SC, Gostout BS, Famuyide AO. Robotic radical hysterectomy in early stage cervical cancer: A systematic review and meta-analysis. Gynecol Oncol 2015; 138(2):457-471

9 Fagotti A, Bottoni C, Vizzielli G, et al. Postoperative pain after conventional laparoscopy and laparoendoscopic single site surgery (LESS) for benign adnexal disease: a randomized trial. Fertil Steril 2011;96(1):255-259.e2

10 Boruta DM, Fagotti A, Bradford LS, et al. Laparoendoscopic singlesite radical hysterectomy with pelvic lymphadenectomy: initial multi-institutional experience for treatment of invasive cervical cancer. J Minim Invasive Gynecol 2014;21(3):394-398

11 Tergas AI, Fader AN. Laparoendoscopic single-site surgery (LESS) radical hysterectomy for the treatment of early stage cervical cancer. Gynecol Oncol 2013;129(1):241-243

12 Sinno AK, Tanner EJ III. Robotic laparoendoscopic single site radical hysterectomy with sentinel lymph node mapping and pelvic lymphadenectomy for cervical cancer. Gynecol Oncol 2015; 139(2):387 
13 Gungor M, Takmaz O, Afsar S, Ozbasli E, Gundogan S. Single-port robotic pelvic bulky lymph node resection: a case report. J Minim Invasive Gynecol 2016;23(7):1030-1031

14 Corrado G, Cutillo G, Mancini E, et al. Robotic single site versus robotic multiport hysterectomy in early endometrial cancer: a case control study. J Gynecol Oncol 2016;27(4):e39

15 Yoo HN, Kim TJ, Lee YY, et al. Single-site robotic surgery in gynecologic cancer: a pilot study. J Gynecol Oncol 2015;26(1): 62-67

16 Bouquet de Joliniere J, Librino A, Dubuisson JB, et al. Robotic surgery in gynecology. Front Surg 2016;3:26

17 Rossi EC, Ivanova A, Boggess JF. Robotically assisted fluorescenceguided lymph node mapping with ICG for gynecologic malignancies: a feasibility study. Gynecol Oncol 2012;124(1):78-82
18 Khoury-Collado F, Glaser GE, Zivanovic O, et al. Improving sentinel lymph node detection rates in endometrial cancer: how many cases are needed? Gynecol Oncol 2009;115(3):453-455

19 Holloway RW, Bravo RA, Rakowski JA, et al. Detection of sentinel lymph nodes in patients with endometrial cancer undergoing robotic-assisted staging: a comparison of colorimetric and fluorescence imaging. Gynecol Oncol 2012;126(1):25-29

20 Furukawa N, Oi H, Yoshida S, Shigetomi H, Kanayama S, Kobayashi $\mathrm{H}$. The usefulness of photodynamic eye for sentinel lymph node identification in patients with cervical cancer. Tumori 2010; 96(6):936-940

21 Crane LM, Themelis G, Buddingh KT, et al. Multispectral real-time fluorescence imaging for intraoperative detection of the sentinel lymph node in gynecologic oncology. J Vis Exp 2010;(44):2225 
